Gut, 1972, 13, 915-919

\title{
The homeostatic function of the colon in acute gastroenteritis
}

\author{
R. D. RUBENS AND H. P. LAMBERT ${ }^{1}$ \\ From the Communicable Diseases Unit, St George's Hospital, London
}

SUMMARY Infants and young children with acute gastroenteritis have been studied with regard to stool electrolyte composition, external electrolyte balance, and aldosterone excretion. At the height of fluid depletion the stool sodium concentrations are low (median $8 \mathrm{~m}$-equiv/l, range 3-58 m-equiv/l). The results indicate that in gastroenteritis the colon is responding homeostatically to a state of secondary hyperaldosteronism, thus assisting in sodium conservation.

The diarrhoea of acute gastroenteritis in infancy and early childhood may be profuse resulting in rapid and severe depletion of body water and electrolytes. Experimental studies (eg, Carpenter, Sack, Feeley, and Steenberg, 1968; Powell, Plotkin, Maenza, Solberg, Catlin, and Forman, 1971) suggest that the diarrhoeal fluid is small intestinal in origin. The electrolyte composition of ileal fluid is normally radically altered by the colon as a consequence of sodium and chloride reabsorption and potassium and bicarbonate secretion (Wrong, 1970), an activity under the influence of aldosterone (Charron, Leme, Wilson, Ing, and Wrong, 1969). The homeostatic response to acute hypovolaemia in gastroenteritis would be the establishment of a state of secondary hyperaldosteronism (Reimold, 1968), presumably mediated via the renin-angiotensin system (Meyer, Ménard, Alexandre, and Weil, 1966). Data indicating the significance of this mechanism in gastroenteritis are presented in this paper.

\section{Patients and Methods}

Seven male children (patients 1-7) aged 3 to 38 months were studied. All had physical signs of severe fluid and electrolyte loss. At admission (time zero) each child was weighed on a Marsden's Weighmaster scales accurate to $\pm 25 \mathrm{~g}$, and venous blood was taken for the estimation of plasma urea, sodium, potassium, and bicarbonate concentrations, plasma osmolality, haemoglobin concentration, and haematocrit. The child was then placed in an Ekco Baby Sitta, a chair with an aperture in the seat to facilitate stool collections, and a urine collecting bag

${ }^{1}$ Requests for reprints should be sent to Professor H. P. Lambert, St George's Hospital, London SW17.

Received for publication 4 September 1972. was attached so that stool and urine samples could be obtained separately. Oral fluid repletion was then begun with half-strength Darrow's (1946) solution (Na 61 m-equiv/l) with $2.5 \%$ glucose. Nothing else was given orally for at least 24 hours and no other treatment was necessary. Each stool and urine specimen passed was analysed separately for sodium and potassium concentrations using the Eel flame photometer, and from these data external electrolyte balance was calculated. The stools were invariably of suitable consistency for direct analysis after centrifugation to remove solid debris. In addition, the osmolality of each stool passed in patients 1 and 2 was estimated by freezing point depression with an Advanced osmometer. Weighings and blood tests were repeated at timed intervals. From the difference between the admission weight and the steady weight on discharge, not the maximum weight reached (Patrick, 1971), the initial fluid depletion was assessed as a percentage of the body weight.

Aliquots of consecutive 24-hour urine collections from time zero were deep frozen at $-20^{\circ} \mathrm{C}$ and were subsequently analysed for their aldosterone content by gas chromatography.

The electrolyte concentration of the first stool passed after admission in another four children (patients 8-11), aged from 6 to 19 months, with severe gastroenteritis, were measured, but further studies were not performed on these children.

The stools of eight children aged 1 to 64 months, who did not have either diarrhoea or any other condition likely to cause hyperaldosteronism, were analysed for electrolyte concentration. These solid stools were analysed by dialysis in vitro using Visking tubing after emulsifying with water and the water content was determined by drying to constant 


\begin{tabular}{|c|c|c|c|c|c|c|}
\hline Patient & $\begin{array}{l}\text { Plasma Osmolality } \\
(\mathrm{mOsm} / \mathrm{kg})\end{array}$ & $\begin{array}{l}\text { Plasma Sodium } \\
(m-e q u i v / l)\end{array}$ & $\begin{array}{l}\text { Plasma Potassium } \\
\text { (m-equiv/l) }\end{array}$ & $\begin{array}{l}\text { Plasma Bicarbonate } \\
\text { (m-equiv/l) }\end{array}$ & $\begin{array}{l}\text { Plasma Urea } \\
(\mathrm{mg} / 100 \mathrm{ml})\end{array}$ & $\begin{array}{l}\text { Haemoglobin } \\
(\mathrm{g} / 100 \mathrm{ml})\end{array}$ \\
\hline $\begin{array}{l}1 \\
2 \\
3 \\
4 \\
5 \\
6 \\
7\end{array}$ & $\begin{array}{l}340 \\
284 \\
316 \\
295 \\
290 \\
330 \\
317\end{array}$ & $\begin{array}{l}153 \\
144 \\
154 \\
139 \\
137 \\
155 \\
138\end{array}$ & $\begin{array}{l}2.5 \\
3.4 \\
4.4 \\
4.0 \\
3.6 \\
3.5\end{array}$ & $\begin{array}{r}6 \\
17 \\
15 \\
13 \\
16 \\
13\end{array}$ & $\begin{array}{r}144 \\
56 \\
89 \\
72 \\
53 \\
82 \\
192\end{array}$ & $\begin{array}{l}10.2 \\
15.1 \\
14.9 \\
15.6 \\
13.9 \\
13.5 \\
14.8\end{array}$ \\
\hline
\end{tabular}

Table I Investigations in patients $1-7$ at the time of admission

weight. The electrolyte concentration of the control stool was then expressed as milliequivalents of sodium or potassium per litre of stool water.

\section{Results}

At the time of admission patients 1-7 were acidotic, uraemic, and plasma osmolalities tended to be high (Table I). In three of them the serum sodium concentration was greater than 150 m-equiv/l, this being an accepted definition of hypernatraemia (Ross and Christie, 1969). The haemoglobin concentrations were high for children of this age, except in patient 1 , and these values fell on rehydration. In retrospect these children were estimated to have lost between 4 and $11 \%$ of their body weight (Table II) with a mean loss of $7.5 \%$.

\begin{tabular}{|c|c|c|c|c|}
\hline \multirow[t]{2}{*}{ Patient } & \multicolumn{3}{|l|}{ Weight $(k g)$} & \multirow{2}{*}{$\begin{array}{l}\text { Percentage } \\
\text { Fluid } \\
\text { Depleted }\end{array}$} \\
\hline & Admission & Maximum & Discharge & \\
\hline 1 & 6.9 & $7 \cdot 7$ & $7 \cdot 7$ & 10 \\
\hline 2 & $9 \cdot 4$ & $10 \cdot 3$ & $10 \cdot 1$ & 7 \\
\hline 3 & $9 \cdot 1$ & $9 \cdot 8$ & $9 \cdot 5$ & 4 \\
\hline 4 & $12 \cdot 7$ & $13 \cdot 8$ & $13 \cdot 6$ & 7 \\
\hline 5 & $14 \cdot 6$ & $15 \cdot 6$ & 15.5 & 6 \\
\hline 6 & $7 \cdot 4$ & 8.5 & $8 \cdot 3$ & 11 \\
\hline 7 & $13 \cdot 8$ & $15 \cdot 0$ & $14 \cdot 8$ & 7 \\
\hline
\end{tabular}

Table II Fluid depletion at the time of admission assessed as a percentage of body weight

\section{STOOL ELECTROLYTES}

The lowest stool sodium concentration recorded and the corresponding potassium concentration, the sodium/potassium ratio, and the time the stool was passed after admission for patients 1-7 are shown in Table III which also includes the same data on the first stool passed in another four children (patients 8-11). The range of sodium concentrations was 3-58 m-equiv/l (median $8 \mathrm{~m}$-equiv/l), that for potassium 17-120 m-equiv/l (median $40 \mathrm{~m}$-equiv/l), and the sodium/potassium $(\mathrm{Na} / \mathrm{K})$ ratios $\mathbf{0} 05-1 \cdot 2$ (median $0 \cdot 16$ ). The sodium and potassium concentrations of consecutive four-hourly stool collections passed by patients 1-7 in the first 24 hours after admission are illustrated in Fig. 1 which shows the medians and ranges. From this it can be appreciated that the initial stool sodium concentrations are low and then increase. The $\mathrm{Na} / \mathrm{K}$ ratios of subsequent stool and urine specimens increase progressively as fluid repletion ensues. The stool and urine $\mathrm{Na} / \mathrm{K}$ ratios followed each other particularly closely in patient 3 (Fig. 2), but the trend was similar in all cases.

The sodium and potassium concentrations in eight control specimens were sodium 12-43 m-equiv/ 1 (median 31.5 m-equiv/l) and potassium 18-80 m-equiv/l (median 50 m-equiv/l).

STOOL OSMOLALITY

The range of osmolalities in 17 stool specimens from

\begin{tabular}{|c|c|c|c|c|}
\hline Patient & $\begin{array}{l}\text { Time Passed (hr) after } \\
\text { Admission }\end{array}$ & $\begin{array}{l}\text { Sodium Concentration } \\
\text { (m-equiv/l) }\end{array}$ & $\begin{array}{l}\text { Potassium Concentration } \\
\text { (m-equiv/l) }\end{array}$ & $\mathrm{Na} / \mathrm{K}$ Ratio \\
\hline 1 & 3 & 6 & 45 & 0.13 \\
\hline 2 & 0 & 4 & 50 & 0.08 \\
\hline 3 & 2.5 & 4 & 70 & 0.05 \\
\hline 4 & 22 & 19 & 120 & $0 \cdot 16$ \\
\hline 5 & 1.8 & 58 & 75 & 0.77 \\
\hline 6 & 2.5 & 3 & 35 & 0.09 \\
\hline 7 & 3 & 11 & 40 & 0.26 \\
\hline 8 & $2 \cdot 8$ & 8 & 35 & 0.23 \\
\hline 9 & 0.8 & 13 & 40 & 0.33 \\
\hline 10 & 0.5 & 3 & 32 & 0.09 \\
\hline 11 & 1.5 & 21 & 17 & 1.2 \\
\hline
\end{tabular}

Table III Lowest stool sodium concentration recorded in patients 1-7 and sodium concentration of the first stool passed after admission by patients 8-11 related to the time the stool was passed, its potassium concentration, and Na/K ratio 


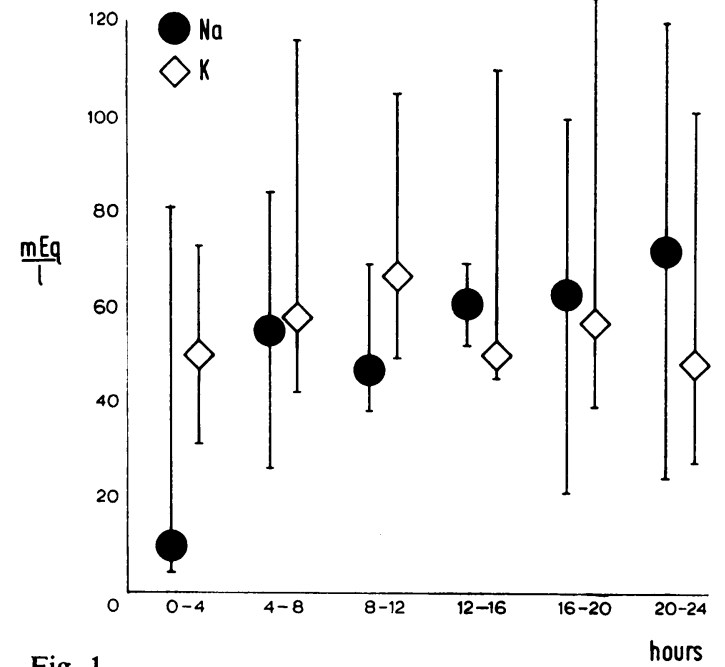

Fig. 1

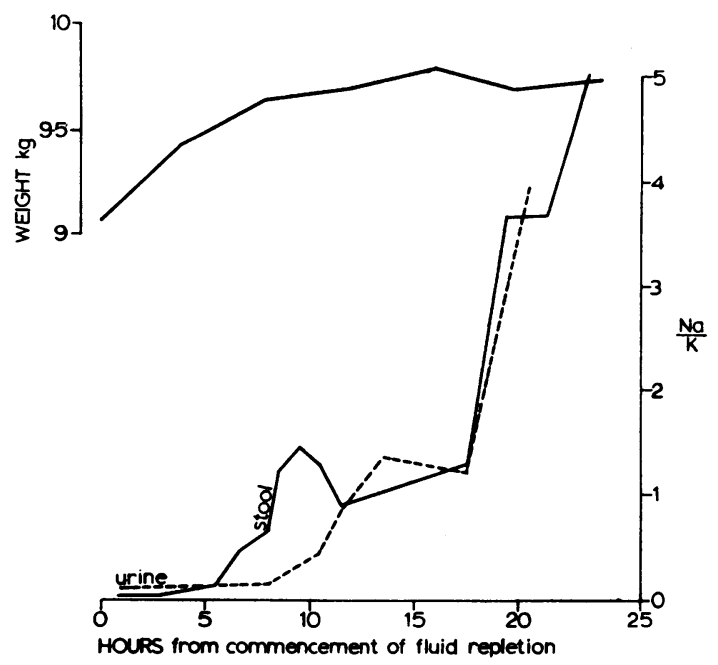

Fig. 2

Fig. 1 The concentration of sodium and potassium in consecutive four-hourly stool collections passed during the first 24 hours after the commencement of fluid and electrolyte repletion in patients 1-7. Medians and ranges are shown.

Fig. 2 The progressive rise in stool and urine $\mathrm{Na} / \mathrm{K}$ ratios and weight gain in patient 3 during the first 24 hours after the commencement of fluid and electrolyte repletion.

patients 1 and 2 in the first 24 hours after admission was $225-365 \mathrm{~m}$-osm $/ \mathrm{kg}$ (median $271 \mathrm{~m}-\mathrm{osm} / \mathrm{kg}$ ).

\section{ELECTROLYTE BALANCE}

The patients (1-7) with full balance studies are all seen to be in strongly positive sodium balance in the first 24 hours after admission (Table IV), although the volumes of diarrhoeal stool are still appreciable (Table V). On the other hand, balance for potassium is less strongly positive and indeed was negative in two patients (Table IV).

\section{ALDOSTERONE EXCRETION}

The aldosterone content of consecutive 24-hour urine volumes after admission are shown in Figure

\begin{tabular}{lllc}
\hline Patient & $\begin{array}{l}\text { Oral Fluids } \\
(\mathrm{m} l)\end{array}$ & $\begin{array}{l}\text { Stool Volume } \\
(\mathrm{ml})\end{array}$ & $\begin{array}{l}\text { Urine Volume } \\
(\mathrm{ml})\end{array}$ \\
\hline 1 & 1420 & 250 & 422 \\
2 & 1905 & 140 & 94 \\
3 & 1510 & 381 & 67 \\
4 & 2658 & 92 & 594 \\
5 & 2630 & 479 & 1085 \\
6 & 2000 & 401 & 80 \\
7 & 2525 & 747 & 445 \\
\hline
\end{tabular}

Table $\mathrm{V}$ External volume balance in patients $1-7$ in the first 24 hours after admission ${ }^{1}$

${ }^{1}$ Insensible losses have not been estimated.

3. (Patient 5 is omitted as serial urinary collections were not obtained.)

\begin{tabular}{|c|c|c|c|c|c|c|c|c|}
\hline \multirow[t]{3}{*}{ Patient } & \multicolumn{4}{|c|}{ Sodium (m-equiv) } & \multicolumn{4}{|c|}{ Potassi.sm (m-equiv) } \\
\hline & \multirow[t]{2}{*}{$\ln$} & \multicolumn{2}{|l|}{ Out } & \multirow[t]{2}{*}{ Balance } & \multirow[t]{2}{*}{ In } & \multicolumn{2}{|l|}{ Out } & \multirow[t]{2}{*}{ Balance } \\
\hline & & Stool & Urine & & & Stool & Urine & \\
\hline $\begin{array}{l}1 \\
2 \\
3 \\
4 \\
5 \\
6 \\
7\end{array}$ & $\begin{array}{r}85 \\
115 \\
91 \\
162 \\
160 \\
122 \\
154\end{array}$ & $\begin{array}{r}16 \\
5 \\
23 \\
3 \\
37 \\
23 \\
29\end{array}$ & $\begin{array}{r}40 \\
4 \\
5 \\
3 \\
42 \\
42 \\
2 \\
2\end{array}$ & $\begin{array}{r}+29 \\
+106 \\
+\quad 63 \\
+156 \\
+81 \\
+97 \\
+123\end{array}$ & $\begin{array}{l}24 \\
32 \\
26 \\
46 \\
46 \\
35 \\
43\end{array}$ & $\begin{array}{l}12 \\
10 \\
25 \\
10 \\
27 \\
22 \\
32\end{array}$ & $\begin{array}{r}5 \\
3 \\
6 \\
24 \\
35 \\
8 \\
7\end{array}$ & $\begin{array}{l}+7 \\
+19 \\
-5 \\
+12 \\
-16 \\
+5 \\
+4\end{array}$ \\
\hline
\end{tabular}

Table IV External electrolyte balance in patients 1-7 in the first 24 hours after admission 

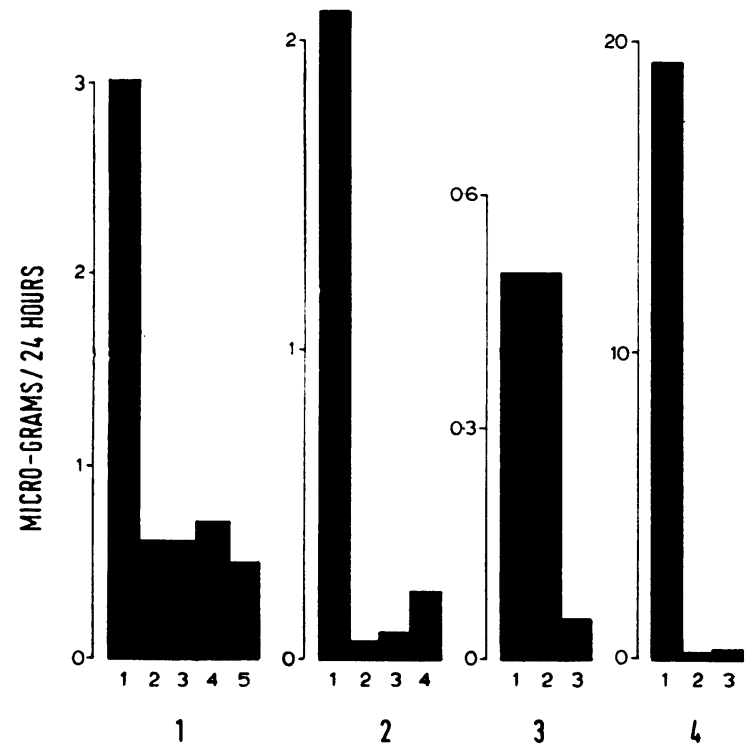

\section{Discussion}

These studies show that in gastroenteritis stool sodium concentrations at the height of fluid depletion are low compared either with our own control values or those from normal adults (Wrong, Metcalf-Gibson, Morrison, $\mathrm{Ng}$, and Howard, 1965). Our findings contrast with the high sodium concentrations usually observed in infantile diarrhoea (Darrow, 1946), although low values have occasionally been recorded in this condition (Teree, MirabalFont, Ortiz, and Wallace, 1965). Previous data have, however, been derived from pooled stool collections usually over periods of 24 hours or more, so that the low sodium concentrations at the height of fluid depletion have not been observed. The stool sodium concentration must, however, be high during the early stages of acute diarrhoea, since the patients show a negative sodium balance, it having presumably fallen during the phase of the illness preceding hospital admission.

It seems likely that in these patients the colon is responding homeostatically to a state of hyperaldosteronism in order to conserve sodium. The Na/K ratio of faecal dialysate bears an inverse relationship to mineralocorticoid activity (Charron et al, 1969) and this ratio has been shown to increase as fluid repletion ensues (Fig. 2). This interpretation of our data is supported by the results of serial urinary aldosterone estimations. It would be expected that, as hypovolaemia is corrected, aldosterone output would diminish; Figure 3 shows a marked diminu- tion of aldosterone excretion in the second or third days after admission.

The initial stools, despite their low sodium concentrations, were not markedly hypotonic as shown by the osmolality measurements. The stools therefore contain other, probably organic, solutes, no doubt derived from food ingested before admission (Fordtran, 1967; Torres-Pinedo, Rivera, and Fernandez, 1966). The dilutional effect of osmotically active substances passing rapidly through the gut provides an alternative explanation for the low sodium concentration of the stool, but this could only be invoked for the period immediately preceding admission, since the children were in markedly negative sodium balance. However, as food intake diminishes with the progress of the illness, we would not expect this factor to be operating at this stage. It seems more likely, therefore, that our data are best accounted for by the operation on the colon of the renin-angiotensin-aldosterone system in response to hypovolaemia.

It is of interest to contrast our results with other diarrhoeal states such as ulcerative colitis and cholera where it has been commented that as stool volumes increase there is a progressive rise in sodium concentration and a corresponding fall in potassium concentration (Fordtran and Dietschy, 1966). This would at first sight appear inconsistent with our own findings. In ulcerative colitis, however, the colonic mucosa is disrupted and its function is, therefore, disturbed with resultant impairment of sodium absorption (Harris and Shields, 1970; 
Edmonds, 1970) whereas in gastroenteritis the colon is anatomically and functionally intact. The situation is also different in cholera, where stool volumes are enormous and, in adults, the electrolyte concentration of stool differs little from that of ileal fluid. However, in children with cholera the sodium content of stool is significantly lower than in adults, while the potassium concentration is about twofold greater (Mahalanabis, Wallace, Kallen, Mondal, and Pierce, 1970), indicating some homeostatic response of the colon in children.

We thank the Board of Governors of St George's Hospital, London, for a research grant, Miss Sheila Linton and her staff for their meticulous care in the collection of specimens, and Mrs P. Maitland of the Department of Chemical Pathology and her staff for assistance with the analyses.

\section{References}

Carpenter, C. C. J., Sack, R. B., Feeley, J. C., and Steenberg, R. W. (1968). Site and characteristics of electrolyte loss and effect of intraluminal glucose in experimental canine cholera. J. clin. Invest., 47, 1210-1220.

Charron, R. C., Leme, C. E., Wilson, D. R., Ing, T. S., and Wrong, O. M. (1969). The effect of adrenal steroids on stool composition, as revealed by in vivo dialysis of faeces. Clin. Sci., 37, 151167.

Darrow, D. C. (1946). The retention of electrolyte during recovery from severe dehydration due to diarrhea. J. Pediat., 28, 515540.
Edmonds, C. J. (1970). Electrical potentials of the sigmoid colon and rectum in irritable bowel syndrome and ulcerative colitis. Gut, 11, 867-874.

Fordtran, J. S. (1967). Speculations on the pathogenesis of diarrhea. Fed. Proc., 26, 1405-1414.

Fordtran, J. S., and Dietschy, J. M. (1966). Water and electrolyte movement in the intestine. Gastroenterology, 50, 263-285.

Harris, J., and Shields, R. (1970). Absorption and secretion of water and electrolytes by the intact human colon in diffuse untreated proctocolitis. Gut, 11, 27-33.

Mahalanabis, D., Wallace, C. K., Kallen, R. J., Mondal, A., and Pierce, N. F. (1970). Water and electrolyte losses due to cholera in infants and small children: a recovery balance study. Pediatrics, 45, 374-385.

Meyer, P., Ménard, J., Alexandre, J. M., and Weil, B. (1966). Correlations between plasma renin, hematocrit and natriuresis. Rev. Canad. Biol., 25, 111-114.

Patrick, J. (1971). Renal excretion of water in infants with acute gastroenteritis. Arch. Dis. Child., 46, 641-645.

Powell, D. W., Plotkin, G. R., Maenza, R. M., Solberg, L. I., Catlin, D. H., and Formal, S. B. (1971). Experimental diarrhea. I. Intestinal water and electrolyte transport in rat salmonella enterocolitis. Gastroenterology, 60, 1053-1064.

Reimold, E. W. (1968). The role of aldosterone in hypernatremic dehydration in infants. Acta paediat. scand., 57, 33-35.

Ross, E. J., and Christie, S. B. M. (1969). Hypernatremia. Medicine (Baltimore), 48, 441-473.

Teree, T. M., Mirabal-Font, E., Ortiz, A., and Wallace, W. M. (1965) Stool losses and acidosis in diarrheal disease of infancy. Pediatrics, 36, 704-713.

Torres-Pinedo, R., Rivera, C. L., Fernandez, S. (1966). Studies on infant diarrhea. II. Absorption of glucose and net fluxes of water and sodium chloride in a segment of the jejunum. J. clin. Invest., 45, 1916-1922.

Wrong, O. M. (1970). In Biochemical Disorders in Human Disease, edited by R. H. S. Thompson and I. D. P. Wootton, 3rd ed., ch. 19. Churchill, London.

Wrong, O. M., Metcalfe-Gibson, A., Morrison, R. B. I., Ng, S. T., and Howard, A. V. (1965). In vivo dialysis of faeces as a method of stool analysis. Clin. Sci., 28, 357-375. 